\title{
The Wafer Alignment Algorithm Regardless of Rotational Center
}

\author{
HyungTae Kim, HaeJeong Yang and SungChul Kim \\ Korea Institute of Industrial Technology \\ South Korea
}

\section{Introduction}

Semiconductor manufacturers prefer automatic machines due to quality, productivity and effectiveness. Compared with other industries, the semiconductor industry has automized the individual steps of a process to a relatively high level. Most of the operators usually learn about wafer placement rather than the principle of the process. But the manual systems do not know the placement of a wafer, so operators should set the initial conditions for the process. Wafer alignment is an operation for correcting the current wafer position in the system coordinate until the wafer is located at the target position. The wafer position varies after loading, so alignment steps are required.

Manual alignment systems need the operators' help every time the wafer is loaded and is actually a time-consuming process, that lowers manufacturing productivity and raises costs. So, automatic alignment can save these time and costs. If the machines have automatic alignment function, wafer processes can be connected automatically. Operators then would only have to check and monitor the processing situation, and fix a problem when it arises. Therefore, one operator can operate more machines, and would not be required to have high process skills. Fig. 1 shows the concept of wafer alignment in the dicing process.

O Passive alignment is related with mechanical structures which persist into external forces without any actuators. A self-constrained mechanism is developed by Choi. When axial force is exerted on a stage, grooves beneath the stage generate internal stress which prevents from moving the stage (Choi et al., 1999). Pyramid and groove mechanism make stacking force under external stress (Slocum \& Weber, 2003).

Active alignment skill using sensors and actuators is applied widely in semiconductor § manufacturing process. Anderson's method (Anderson et al, 2004) is based on cross-relation between a defined template and an inspected image. He segmented the pixels around a peak and interpolated under sub-pixel level. Misalignment can be detected by Moire effect and laser beam. PZT actuators are applied to remove misalignment in lithography (Fan et

(s) al., 2006). Machine vision is a common device to detect misalignment in wafer aligment ¿ (Hong \& Fang, 2002).

O We have developed an algorithm for wafer alignment. This alignment algorithm was derived from rigid body transformation or object transformation. The algorithm was based on the simultaneous motion of $x-y-\theta$ axes in 2D space. A 2-step algorithm has a simple form which can be written by $2 \times 2$ matrix operations. The magnitude of misalignment was 
reduced in base of macro and micro inspection data(Kim et al., 2004). The matrix was expanded with $4 \times 4$, and $\theta$ was included in the equation. So, the alignment variables of $x-y-$ $\theta$ can be calculated within one equation(Kim et al, 2004), (Kim et al, 2006). The manufacturing condition which was varied to be ideal conditions, affected the quality of alignment. Sometimes the misalignment did not become zero after only macro-micro alignment. In this case, the problem can be solved by iterative alignment equation, which is similar to numerical algorithms(Kim et al, 2007). The convergence speed of the iteration can be controlled by the convergence constant. This constant can prevent numerical vibration. The convergence analysis method, similar to a numerical method, is proposed(Kim et al, 2006). We tried to obtain the exact solution in these studies, but they found that the solutions can be obtained from an estimated equation. The idea in this study came from the estimated method. The equation could be simplified by making a few assumptions of the wafer alignment condition. The derived formula did not have the terms for rotational center, which was impossible to measure exactly. The alignment results showed that the performance of the proposed algorithm was similar to the exact solution, and that the error convergence speed can be controlled.

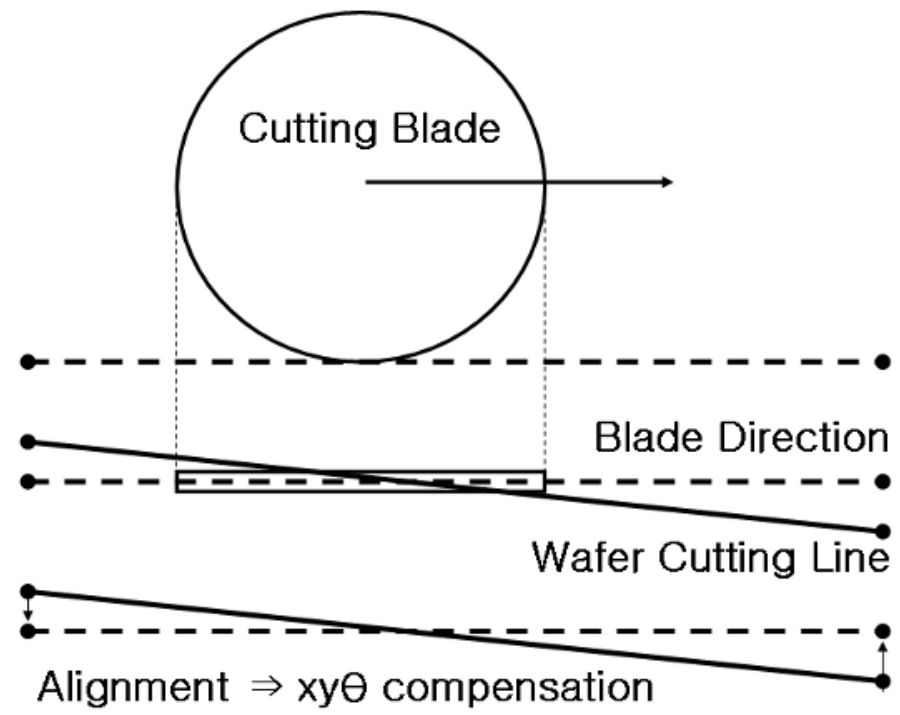

Fig. 1. Concept of wafer alignment in dicing process

\section{Review of 2D alignment model}

\subsection{Coordinate transformation for alignment(Kim et al, 2004)}

The machine coordinate in the alignment system has three variables $-x, y$ and $\theta$. Let be the $\mathrm{P}(\mathrm{x}, \mathrm{y})$ original coordinate, and $\mathrm{P}^{\prime}\left(\mathrm{x}^{\prime}, \mathrm{y}^{\prime}\right)$ be the transformed coordinate. The each coordinate can be shown as follows

$$
P=\left(\begin{array}{llll}
x & y & \theta & 1
\end{array}\right)^{T} \quad P^{\prime}=\left(\begin{array}{llll}
x^{\prime} & y^{\prime} & \theta^{\prime} & 1
\end{array}\right)^{T} \quad P=\left(\begin{array}{llll}
C_{x} & C_{y} & 0 & 0
\end{array}\right)^{T}
$$


The alignment space is on $2 \mathrm{D}$, the alignment procedure carries out translation and rotational motion. The movement can be described by rigid body transformation and the coordinate after the motion can be calculated simply by multiplying matrices. The notation of the translational matrix usually has a ' $\mathrm{T}$ ', the rotational matrix has an ' $\mathrm{R}$ ' and the center of rotation has a ' $C$ '. Then the transformation is formulated by equation (2).

$$
P^{\prime}=T\{R(P-C)+C\}
$$

TR matrices in the wafer alignment system can be derived as equations (3) and (4), which are $4 \times 4$ matrices.

$$
\begin{gathered}
T=\left[\begin{array}{cccc}
1 & 0 & 0 & \Delta x \\
0 & 1 & 0 & \Delta y \\
0 & 0 & 1 & 0 \\
0 & 0 & 0 & 1
\end{array}\right] \\
R=\left[\begin{array}{ccccc}
\cos \Delta \theta & -\sin \Delta \theta & 0 & 0 \\
\sin \Delta \theta & \cos \Delta \theta & 0 & 0 \\
0 & 0 & 1 & \Delta \theta \\
0 & 0 & 0 & 1
\end{array}\right]
\end{gathered}
$$

\subsection{Basic alignment algorithm(Kim et al, 2006)}

The wafer has marks for alignment. The ideal mark position $P_{t}$ is stored when the wafer is perfectly aligned. Misalignment is calculated from the current position $\mathrm{P}_{\mathrm{c}}$. The vision system inspects the location of the mark on the screen. These mark positions can be defined as follows.

$$
P_{t}=\left(\begin{array}{llll}
x_{t} & y_{t} & \theta_{t} & 1
\end{array}\right)^{T} P_{c}=\left(\begin{array}{llll}
x_{c} & y_{c} & \theta_{c} & 1
\end{array}\right)^{T}
$$

When the current position of the mark is deviated from the ideal one, the resulting displacement can be defined as 4 . The mark position in the machine can be obtained from the target position and the displacement by equation (6).

$$
P_{c} \approx P_{t}+\Delta=\left(x_{c}+\Delta x, y_{c}+\Delta y, \theta_{c}+\Delta \theta, 1\right)^{T}
$$

If the current position is compensated with an arbitrary value $a=\left(\alpha_{x}, \alpha_{y}, \alpha_{\theta}, 0\right)$, the mark will be located at the target position. So, an alignment algorithm $f(x)$ can be written by equation (7).

$$
f\left(P_{c}, \alpha\right)-P_{t}=0
$$

$\mathrm{f}(\mathrm{Pc}, \mathrm{a})$ can be replaced with the equation from the rigid body transformation. The result is shown as (8). The $T$ and $R$ have the unknown compensation variable for the current position. 


$$
T\left\{R\left(P_{c}-C\right)+C\right\}-P_{t}=0
$$

The plus direction between the mathematical coordinate and vision can be reverse, and the relation can be written by vision direction matrix $D_{v}$ whose diagonal terms have a value of either +1 or -1 and the other terms are zero.

$$
T\left\{R\left(P_{t}+D_{v} \Delta-C\right)+C\right\}-P_{t}=0
$$

The direction problem can occur between the math coordinate and the machine, and the machine direction matrix $D_{m}$ has the similar characteristics as $D_{v}$.

$$
\beta=D_{m} \alpha \beta=\left(\begin{array}{llll}
\beta_{x} & \beta_{y} & \beta_{\theta} & 1
\end{array}\right)^{T}
$$

The unknown a can be calculated from the equation, and (11) and (12) are the exact solution in the case when two points are inspected to align a line.

$$
\begin{gathered}
\alpha_{x n}=x_{t n}-C_{x}-\left(x_{c n}-C_{x}\right) \cos \theta_{n}+\left(y_{c n}-C_{y}\right) \sin \theta_{n} \\
\alpha_{y n}=y_{t n}-C_{y}-\left(x_{c n}-C_{x}\right) \sin \theta_{n}-\left(y_{c n}-C_{y}\right) \cos \theta_{n} \\
\tan \alpha_{\theta}=\frac{\left(x_{c 1}-x_{c 2}\right)\left(y_{t 1}-y_{t 2}\right)-\left(y_{c 1}-y_{c 2}\right)\left(x_{t 1}-x_{t 2}\right)}{\left(x_{t 1}-x_{t 2}\right)\left(x_{c 1}-x_{c 2}\right)+\left(y_{t 1}-y_{t 2}\right)\left(y_{c 1}-y_{c 2}\right)}
\end{gathered}
$$

\section{Centerless model}

\subsection{Simplification}

The equations (11) and (12) are the exact solution, but estimated solutions have been used for many numerical problems. Some variables can be erased by geometric relations and alignment conditions. Fig. 2 shows the general condition for wafer alignment in the dicing process. First, angular misalignment in the process is within $\pm 2^{\circ}$, which means $\sin \alpha \approx \alpha$ and $\cos \alpha \approx 1$. the equation (11) can be written as follows

$$
\begin{aligned}
& \alpha_{x n}=x_{t n}-x_{c n}+\left(y_{c n}-C_{y}\right) \sin \alpha_{\theta n}=-\Delta_{x n}+\left(y_{c n}-C_{y}\right) \alpha_{\theta n} \\
& \alpha_{y n}=y_{t n}-y_{c n}-\left(x_{c n}-C_{x}\right) \sin \alpha_{\theta n}=-\Delta_{y n}-\left(x_{c n}-C_{x}\right) \alpha_{\theta n}
\end{aligned}
$$

Second, inspection is carried out at two points, and the compensation value is the average, $\mathrm{a}=\left(\mathrm{a}_{1}+\mathrm{a}_{2}\right) / 2$. And the inspection points are axis-symmetric at the rotational center, $2 \mathrm{C}_{\mathrm{x}}-\left(\mathrm{x}_{\mathrm{c} 1}+\mathrm{x}_{\mathrm{c} 2}\right)=0$. Another assumption is that the mark position is defined near the rotational center, $2 \mathrm{C}_{\mathrm{y}}-\left(\mathrm{y}_{\mathrm{c} 1}+\mathrm{y}_{\mathrm{c} 2}\right)=0$. Therefore, the equation (13) can be expressed as (14).

$$
\begin{aligned}
& \alpha_{x n}=-\left(\Delta_{x 1}+\Delta_{x 2}\right) / 2 \\
& \alpha_{y n}=-\left(\Delta_{y 1}+\Delta_{y 2}\right) / 2
\end{aligned}
$$

The $\mathrm{x}$-stroke of two points is actually constant, $1=\mathrm{x}_{\mathrm{t} 2}-\mathrm{x}_{\mathrm{t} 1} \approx \mathrm{x}_{\mathrm{c} 2}-\mathrm{x}_{\mathrm{c} 1}$ because the $\mathrm{x}$ variation by misalignment is much smaller than the moving stroke. The $y$-stroke of two points is actually zero, $\mathrm{y}_{\mathrm{t} 2}-\mathrm{y}_{\mathrm{t} 1}=0$. Equation (15) is derived from these relations. 


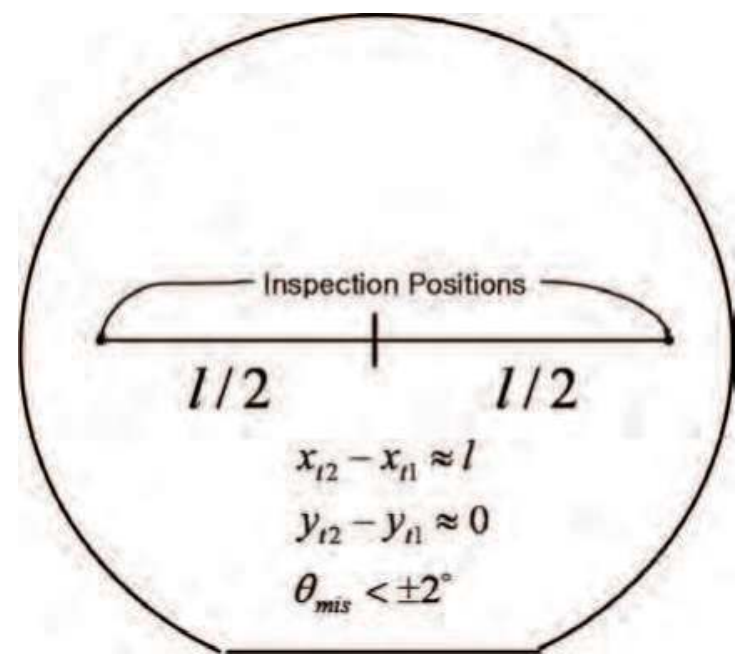

Fig. 2. General conditions for wafer alignment

$$
\tan \alpha_{\theta} \approx \alpha_{\theta}=\frac{\left(\Delta_{y 2}-\Delta_{y 1}\right)}{l}
$$

The derived equations are much simpler and have no center terms for rotation. Considering the wafer alignment system, there are three centers, as shown Fig. 3: rotational center, wafer center, and chuck center. The positions of these three centers are different, but cannot be measured exactly or cannot be fixed at the same position. Centerless algorithm cannot give an exact solution, but an estimated one, so the iteration step is necessary.

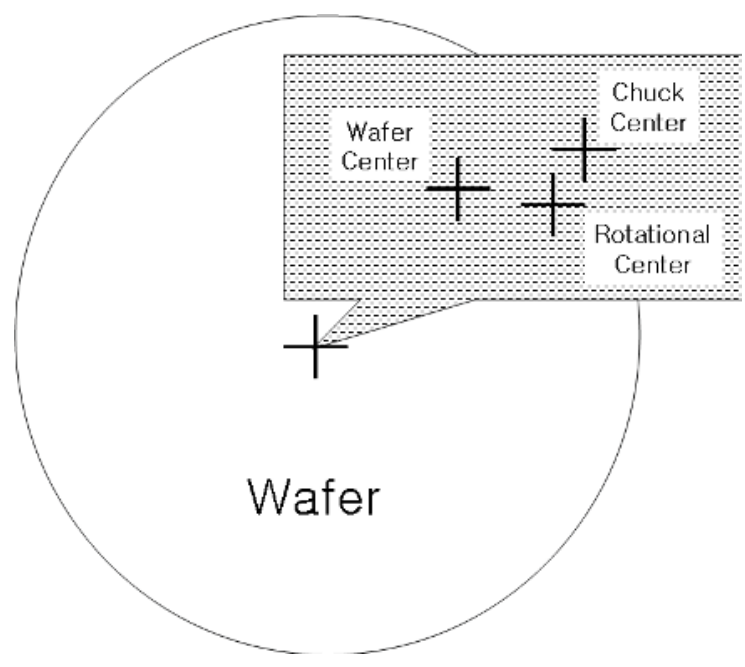

Fig. 3. Different Centers on alignment table 


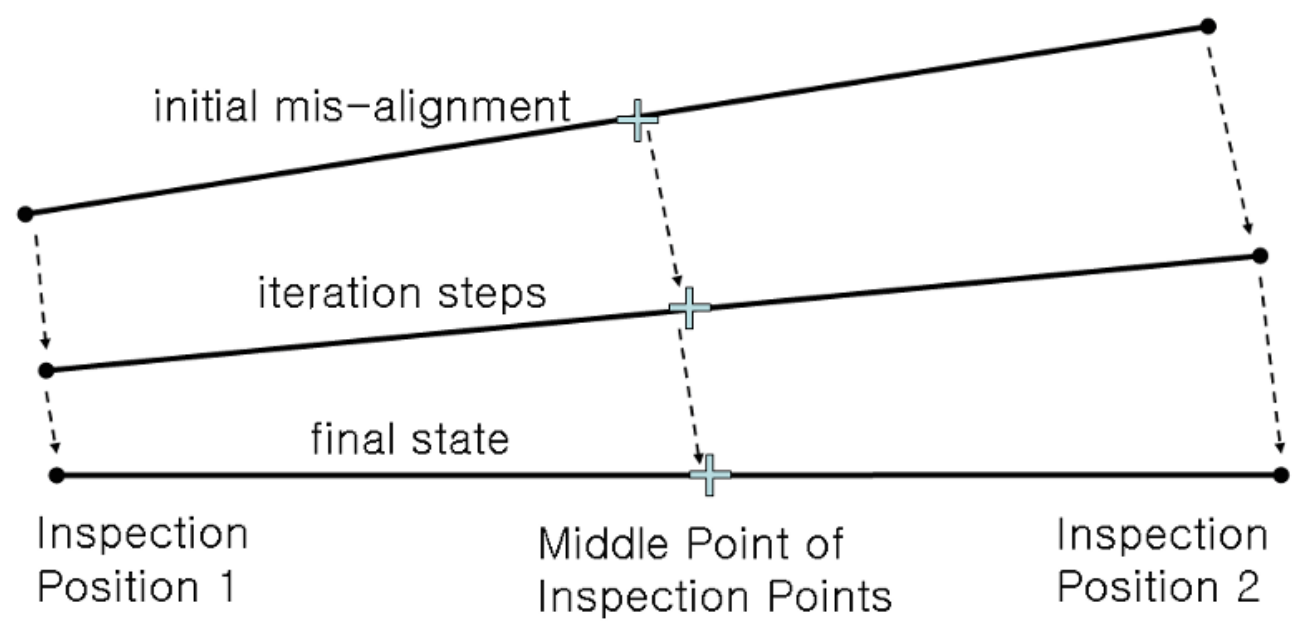

Fig. 4. Concept of movement for the points in alignment

The equation can be explained in another way. Fig. 4 shows the virtual alignment procedure. The inspection positions are located at both ends of the lines, and the middle point can represent the inspection points. The misalignment of the middle point can be estimated from the average of the misalignment on the two points. And the compensation value of the middle point is approximately equal to the magnitude of the misalignment, and the result can be written as (14) and (15).

\subsection{Iteration and convergence}

The alignment properties are estimated, and it is possible that the misalignment cannot be zero after the first alignment. And manufacturing conditions can vary and are different from the ideal condition. The alternative is the iterative alignment, which is carried out until the misalignment decreases under tolerance level. Compensation values are added to the current position, and the i-th step of the alignment can be written as equation (16). It is necessary to control convergence speed, and the convergence constant is defined as $\eta$.

$$
{ }^{i+1} P_{c}={ }^{i} P_{c}+\eta \times{ }^{i} \beta
$$

Misalignment can be defined as the magnitude of the deviation, as shown in (17). The iteration is terminated when the misalignment becomes smaller than tolerance $\varepsilon$.

$$
\left|{ }^{i} \Delta\right|=\sqrt{\frac{\left(\Delta_{x 1}^{2}+\Delta_{x 2}^{2}\right)+\left(\Delta_{y 1}^{2}+\Delta_{y 2}^{2}\right)}{2}<\varepsilon}
$$


As the automatic alignment proceeds, the numerical position on the machine is compensated. The magnitude of the compensation value $\beta$ will decrease by the number of iterations. $\gamma$ is defined as the total amount of the compensation or difference between initial position and current position. The $\gamma$ will be converged to an arbitrary value if the alignment is done well.

$$
{ }^{i+1} \gamma={ }^{i} \gamma+\eta \times{ }^{i} \beta={ }^{i} P_{c}-{ }^{0} P_{c}
$$

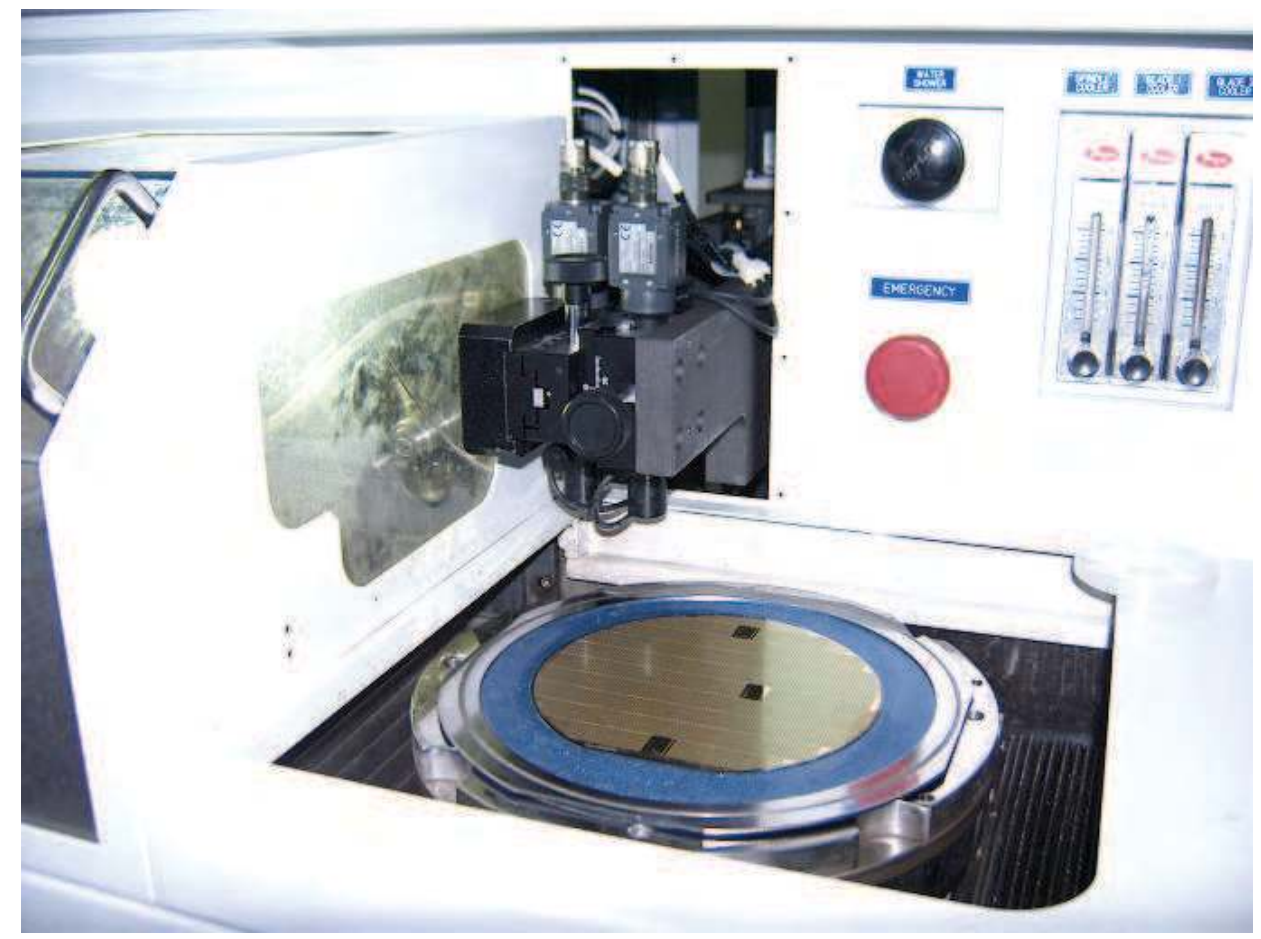

Fig. 5. Photo of automatic wafer dicing machine

\section{Experiment}

\subsection{Dicing machine}

The algorithm was tested on the wafer dicing machine. The machine had 4 axes $-\mathrm{x}, \mathrm{y}, \mathrm{z}$ and $\theta$. Because the $\mathrm{z}$ axis is actually used only for cutting action, it was excluded for alignment. Each axis is composed of a ball-screw and LM guide. The axes were accurate to the microlevel. Fig. 5 shows a picture of the dicing machine, and table 1 shows its specifications. The align mark was inspected with a PCI frame grabber, which has 0.1 sub-pixel accuracy. Two cameras were connected to the frame grabber. Very small lenses were attached to the cameras, which had same magnifications because of the align patterns. 


\begin{tabular}{|c|c|c|}
\hline contents & name/axis & specification \\
\hline $\begin{array}{l}\text { resolution } \\
\begin{array}{c}\text { linear scale } \\
\text { pitch }\end{array} \\
\text { motor } \\
\text { backlash }\end{array}$ & $\begin{array}{l}x \\
y \\
\theta \\
y \\
x \\
y \\
\theta \\
x \\
y \\
\theta \\
x \\
y\end{array}$ & $\begin{array}{c}1 \mu \mathrm{m} \\
0.2 \mu \mathrm{m} \\
2.0 \times 10^{-4} \mathrm{deg} \\
10000 \mathrm{ps} / \mathrm{mm} \\
10 \mathrm{~mm} / \mathrm{rev} \\
4 \mathrm{~mm} / \mathrm{rev} \\
1 / 100 \text { (harmonic driver) } \\
10000 \mathrm{ps} \\
20000 \mathrm{ps} \\
18000 \mathrm{ps} \\
7 \mu \mathrm{m} \\
0 \mu \mathrm{m}\end{array}$ \\
\hline camera & $\begin{array}{l}\text { model } \\
\text { pixel } \\
\text { FOV } \\
\text { exposure }\end{array}$ & $\begin{array}{c}\text { Sony XC-HR50 } \\
640 \times 480 \\
1.31 \mathrm{~mm} \times 0.98 \mathrm{~mm} \\
20 \mathrm{~ms}\end{array}$ \\
\hline frame grabber & $\begin{array}{l}\text { model } \\
\text { Precision } \\
\text { library }\end{array}$ & $\begin{array}{c}\text { Cog8501 } \\
0.1 \text { sub-pixel } \\
\text { Vision Pro } 3.5\end{array}$ \\
\hline
\end{tabular}

Table 1. Specification of Machine

\subsection{Procedure}

First, a wafer was aligned manually to get a standard pattern on an inspected image. The shape of align pattern in the experiment was the cross mark. The machine was moved to search for the best pattern of a high-quality image. The image of the mark and training results were stored. The inspection positions were defined at the mechanical positions when the align pattern was located at the center of the screen. The inspection positions were defined for dicing lines of $\theta=0^{\circ}$ and $\theta=90^{\circ}$.

After the position definition, the wafer was released from the table and placed again manually to give random errors. The system began aligning from $0^{\circ}$ alignment, and then it proceeded to $90^{\circ}$ alignment. The magnifications of the lenses were the same, and the macroalignment had no meaning. Three lines were aligned for $0^{\circ}$, and ten for $90^{\circ}$. The deviations were stored at each inspection points. The compensation values were obtained from the deviation. The system axes were compensated by these values, so the inspection positions were also changed. The inspection and compensation were iterated until the misalignment was under 1.0 pixel. The convergence constant $\eta$ was varied from 0.5 to 1.5 without releasing the wafer. The experiment was repeated for 15 cases of mark locations on the vision screen, as shown in the previous report. 


\section{Result}

Wafers were aligned successfully for the 15 cases. One of the cases is shown in this paper. The variation of $y^{\prime} s$ is shown in Fig. 6 - Fig. 11. The horizontal axis of the plots was the number of iterations, and the vertical axis was the compensation value. The thick-black line, called 'org' is the result obtained by the use of the original equation before the simplification. The convergent path was varied by $\eta$, and the convergent speed can be controlled. When the $\eta$ increased, the path showed a bigger overshoot and sharp edges. This kind of trend always occurred when the value was above 1.0. This also makes the alignment time longer. When the $\eta$ drcreases, the path showed a smooth shape and longer alignment time. This trend always occurred when the $\eta$ was below 1.0. There was no overshoot for this case. The original equation provided the fastest convergence for a case, but the result showed that the simplified equation was also effective for application. The best value for $\gamma_{x}$ was 1.1, but that of $\gamma_{y}$ was 1.0. The response of the best case was delayed about 1.0 step for the case of the original equation.

\section{Conclusion}

The proposed equation for wafer alignment was derived from object transformation and simplified with some assumptions made. The alignment algorithm had the iteration terms with the convergence constant. The algorithm was applied to a dicing machine. After setup, the wafers were placed manually, and aligned with the proposed algorithm. The iteration was terminated until the measured misalignment became below 1.0 vision pixel. The convergence constant $\eta$ varied from 0.5 to 1.5 for each case. For all 15 cases, the alignment was finished. The result showed that the simplified algorithm converged slower than the original equation. But the delay was about 1.0 step according to the convergent constant. When the $\eta$ was above 1.0, the response curve had an overshoot and sharp edges. But the curve had smoothness and slower response when the $\eta$ was below 1.0. The alignment algorithm was simple so that it can be applied to PLC-base systems.

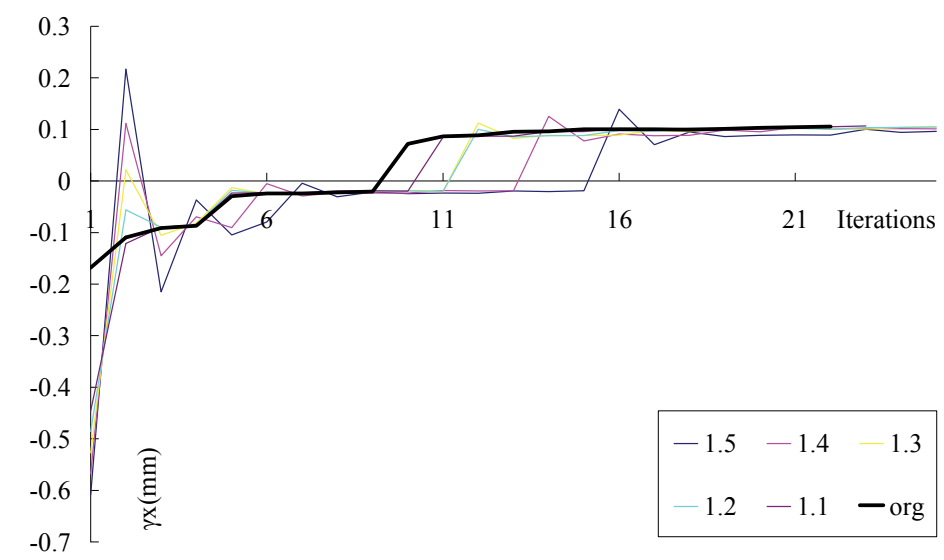

Fig. 6. Variation of $\gamma_{x}$ by iteration $\left(\gamma_{x}=1.1-1.5\right)$ 


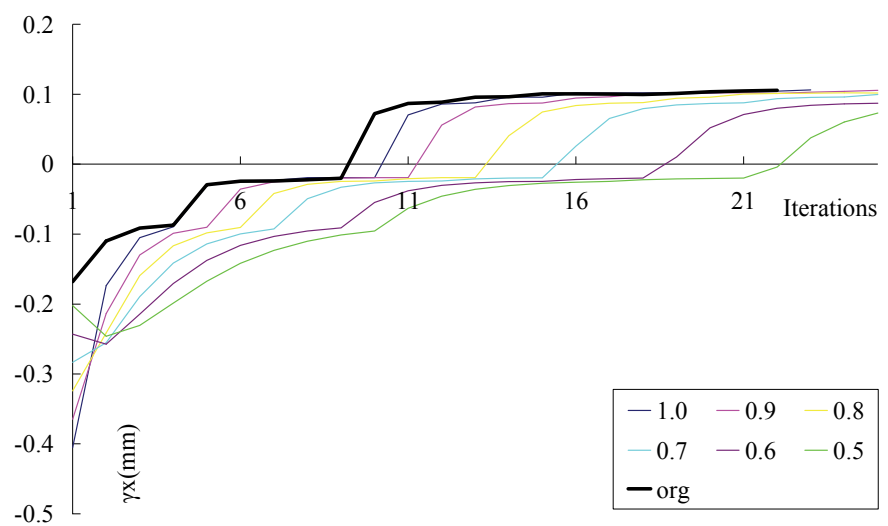

Fig. 7. Variation of $\gamma_{x}$ by iteration $\left(\gamma_{x}=0.5-1.0\right)$

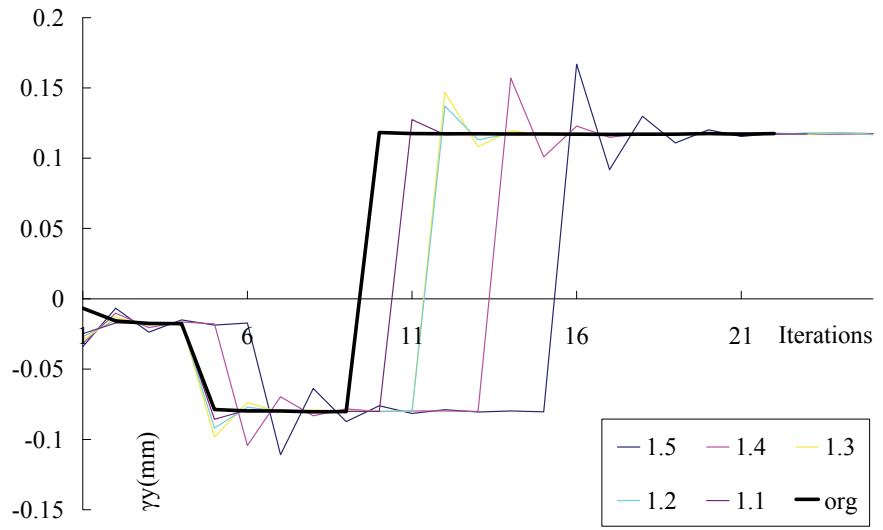

Fig. 8. Variation of $\gamma_{y}$ by iteration $\left(\gamma_{y}=1.1-1.5\right)$

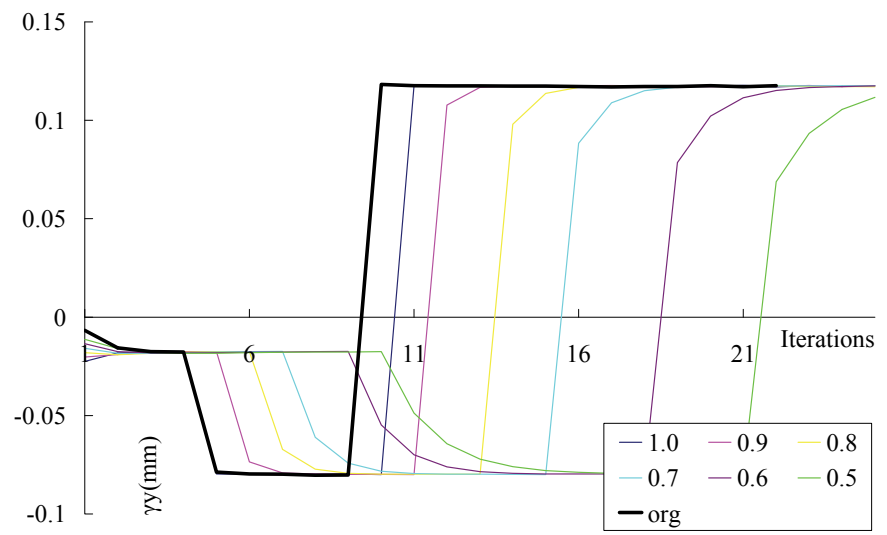

Fig. 9. Variation of $\gamma_{y}$ by iteration $\left(\gamma_{y}=0.5-1.0\right)$ 


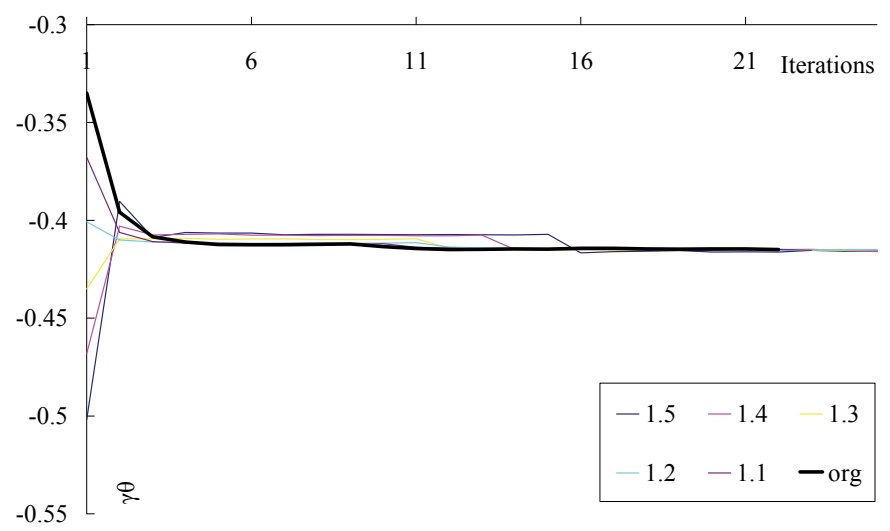

Fig. 10. Variation of $\gamma_{\theta}$ by iteration $\left(\gamma_{\theta}=1.1-1.5\right)$

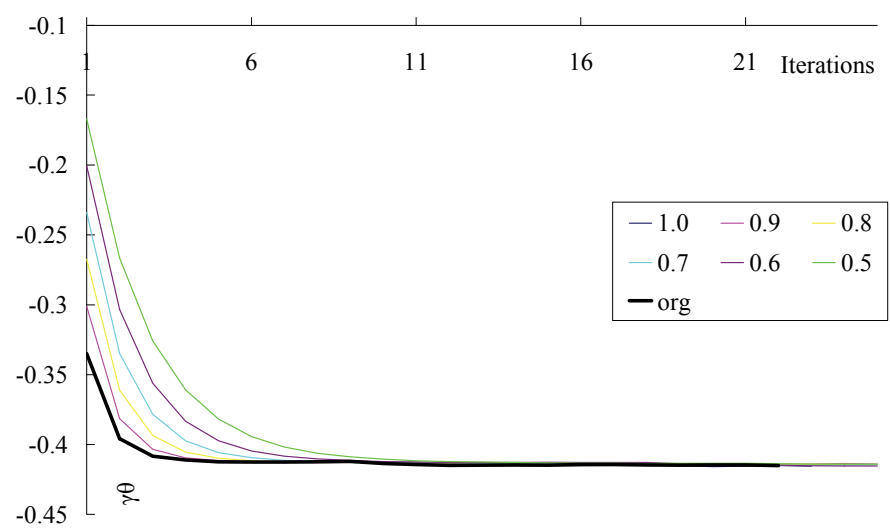

Fig. 11. Variation of $\gamma_{\theta}$ by iteration $\left(\gamma_{\theta}=0.5-1.0\right)$

\section{References}

Choi, M. H.; Koh, H. J. , Yoon, E. S., Shin, K. C. \& Song, K. C., (1999) Self-Aligning Silicon Groove Technology Platform for the Low Cost Optical Module, Proceedings of Electronic Components and Technology Conference, pp. 1140-1144, ISBN 0-7803-5231-9, San Diego, June 1999, IEEE, CA

Slocum, A.H. \& Weber, A.C. (2003). Precision passive mechanical alignment of wafers. Journal of Microelectromechanical Systems, Vol. 12, No. 6, (Dec. 2003) pp. 826-834, ISSN 1057-7157

Anderson, E. H.; Ha, D. \& Liddle, J. A. (2004) Sub-pixel alignment for direct-write electron beam lithography. Microelectronic Engineering, Vol. 73-74, (June 2004) pp. 74-79, ISSN 0167-9317 
Fan, X.; Zhang, H., Liu, S. Hu, X. \& Jia, K. (2006) NIL - A low cost and high throughput MEMS fabrication method compatible with IC manufacturing technology. Microelectronics Journal, Vol. 37, No. 2, (Feb 2006) pp. 121-126, ISSN 0026-2692

Hong, S. \& Fang, M. (2002) A Hybrid Image Alignment System for Fast Precise Pattern Localization. Real-Time Imaging, Vol. 8, No. 1, (Feb. 2002) 23-33, ISSN 1077-201

Kim, H. T.; Song, C. S. \& Yang, H. J., (2004) 2-step algorithms for automatic alignment. Microelectronics Reliability, Vol.44, No.6, (July 2004) pp. 1165-1179, ISSN 0026-2714

Kim, H. T.; Song, C. S. \& Yang, H. J. (2004) Matrix form of automatic alignment algorithm in 2D space, Proceedings of the IEEE International Conference on Mechatronics, pp. 465469, ISBN 0-7803-8599-3, Istanbul, June 2004, IEEE, Turkey

Kim, H. T.; Song, C. S. \& Yang, H. J. (2006) Algorithm for automatic alignment in 2D space by object transformation, Microelectorics Reliability, Vol.46, No.1, (Jan. 2006) pp. 100108, ISSN 0026-2714

Kim, H. T.; Yang, H. J. \& Baek, S. Y. (2007) Iterative algorithm for automatic alignment by object transformation, Microelectorics Reliability, Vol. 47, No. 6, (June 2007) pp. 972985, ISSN 0026-2714

Kim, H. T. ; Yang H. J. \& Kim, S. C., (2006) Convergence analysis of wafer alignment algorithm based on object transformation, Proceedings of the IEEE International Conference on Industrial Electorics Application, pp.1690-1695, ISBN 0-7803-9514-X, Singapore, May 2006, Singapore 


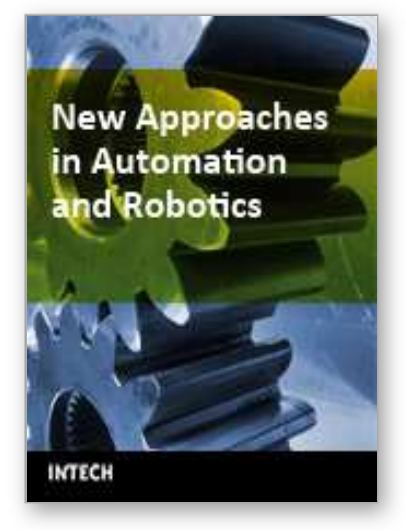

\author{
New Approaches in Automation and Robotics \\ Edited by Harald Aschemann
}

ISBN 978-3-902613-26-4

Hard cover, 392 pages

Publisher I-Tech Education and Publishing

Published online 01, May, 2008

Published in print edition May, 2008

The book New Approaches in Automation and Robotics offers in 22 chapters a collection of recent developments in automation, robotics as well as control theory. It is dedicated to researchers in science and industry, students, and practicing engineers, who wish to update and enhance their knowledge on modern methods and innovative applications. The authors and editor of this book wish to motivate people, especially under-graduate students, to get involved with the interesting field of robotics and mechatronics. We hope that the ideas and concepts presented in this book are useful for your own work and could contribute to problem solving in similar applications as well. It is clear, however, that the wide area of automation and robotics can only be highlighted at several spots but not completely covered by a single book.

\title{
How to reference
}

In order to correctly reference this scholarly work, feel free to copy and paste the following:

HyungTae Kim, HaeJeong Yang and SungChul Kim (2008). The Wafer Alignment Algorithm Regardless of Rotational Center, New Approaches in Automation and Robotics, Harald Aschemann (Ed.), ISBN: 978-3902613-26-4, InTech, Available from:

http://www.intechopen.com/books/new_approaches_in_automation_and_robotics/the_wafer_alignment_algorit hm_regardless_of_rotational_center

\section{INTECH}

open science | open minds

\author{
InTech Europe \\ University Campus STeP Ri \\ Slavka Krautzeka 83/A \\ 51000 Rijeka, Croatia \\ Phone: +385 (51) 770447 \\ Fax: +385 (51) 686166 \\ www.intechopen.com
}

\author{
InTech China \\ Unit 405, Office Block, Hotel Equatorial Shanghai \\ No.65, Yan An Road (West), Shanghai, 200040, China \\ 中国上海市延安西路65号上海国际贵都大饭店办公楼405单元 \\ Phone: +86-21-62489820 \\ Fax: +86-21-62489821
}


(C) 2008 The Author(s). Licensee IntechOpen. This chapter is distributed under the terms of the Creative Commons Attribution-NonCommercialShareAlike-3.0 License, which permits use, distribution and reproduction for non-commercial purposes, provided the original is properly cited and derivative works building on this content are distributed under the same license. 